\title{
Avaliação dos resultados cirúrgicos com a técnica da ressecção do músculo de Müller-conjuntiva no tratamento da blefaroptose
}

\author{
Evaluation of thesurgery resultsof Müller's muscle-conjunctival resection in the treatment \\ of ptosis
}

\author{
Serge Morax ${ }^{1}$ \\ Tânia Pereira Nunes ${ }^{2}$ \\ Houyem Ben-Ayed ${ }^{3}$ \\ Mehrad Hamedani $^{4}$ \\ Suzana Matayoshi ${ }^{5}$
}

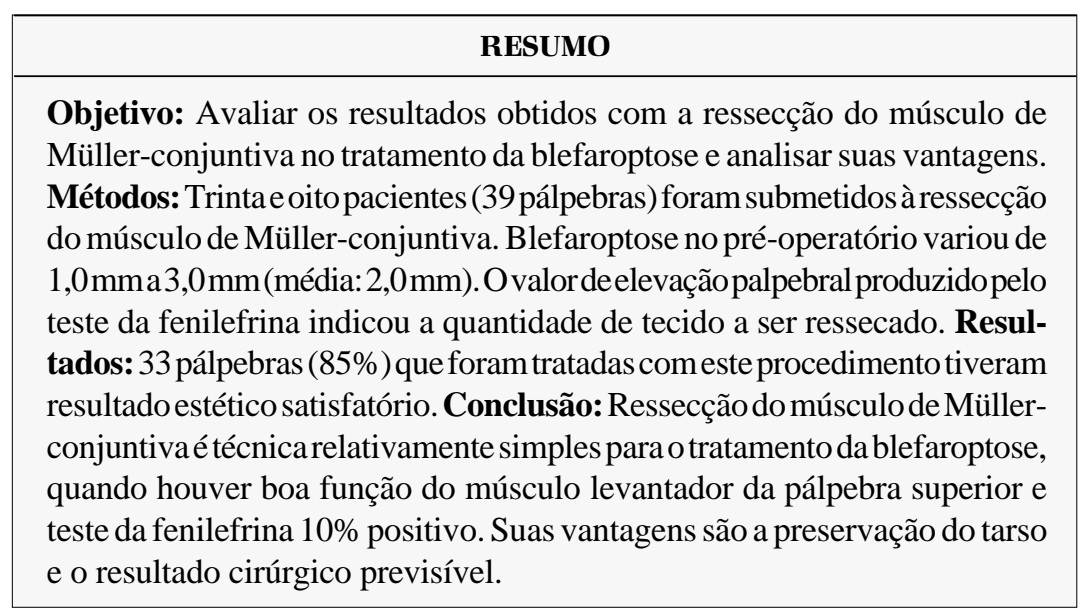

Descritores: Blefaroptose/cirurgia; Palpebras/cirurgia; Conjuntiva/cirurgia; Fenilefrina/ uso diagnóstico; Resultado de tratamento
Trabalho realizado no setor de Cirurgia Órbito-Palpebral da Fondation Ophtalmologique Adolphe de Rothschild. Paris (França).

${ }^{1}$ Médico chefe do setor de Cirurgia Órbito-Palpebral da Fondation Ophtalmologique A. de Rothschild. Paris (França).

${ }^{2}$ Médica pós-graduanda do departamento de Oftalmologia da Faculdade de Medicina da Universidade de São Paulo (USP). São Paulo (SP). Ex-estagiária do setor de Cirurgia Órbito-Palpebral da Fondation Ophtalmologique A. de Rothschild. Paris (França).

Médico assistente do setor de Cirurgia Órbito-Palpebral da Fondation Ophtalmologique A. de Rothschild. Paris (França).

${ }^{4}$ Médico assistente do setor de Cirurgia Órbito-Palpebral da Fondation Ophtalmologique A. de Rothschild. Paris (França).

Médica doutora assistente do setor de Plástica Ocular da Faculdade de Medicina da USP. São Paulo (SP).

Endereço para correspondência: Tânia P. Nunes Rua Cristiano Viana, 116 apto 32 - São Paulo (SP)

CEP 05411-000

E-mail: nunes32@bol.com.br

Recebido para publicação em 10.06.2003

Versão revisada recebida em 15.09.2004

Aprovação em 06.04.2005

\section{INTRODUÇÃO}

A correção da blefaroptose é sempre um desafio para o oftalmologista, pois sua expectativa estética é máxima. Em 1961 Fasanella e Servat descreveram uma técnica simples e rápida para a correção da ptose palpebral, de 3 a $4 \mathrm{~mm}$, com boa função do músculo levantador da pálpebra superior (MLPS). A técnica original consistiu na ressecção em bloco do MLPS, músculo de Müller (MM), tarso e conjuntiva (C) ${ }^{(1)}$.

Em 1975 Putterman e Urist, descreveram uma técnica semelhante à descrita pelos autores citados anteriormente, ressecando em bloco o MM e a conjuntiva. Este procedimento mostra-se eficaz em quadros de blefaroptose que apresentam boa função do MLPS e teste da fenilefrina positivo ${ }^{(2)}$. Sua vantagem é a preservação do tarso.

O teste da fenilefrina é realizado em casos de blefaroptoses mínimas e moderadas com o objetivo de verificar a participação do MM na alteração palpebral e assim indicar a técnica cirúrgica mais apropriada; a droga estimula diretamente os receptores $\alpha$ adrenérgicos, produzindo a contração do MM. O teste consiste em avaliar a diferença da altura da margem palpebral antes e após 10 minutos de instilação do colírio de fenilefrina $10 \%$ no fundo de saco conjuntival superior do lado ptótico; se a pálpebra superior elevase, apresentando um nível palpebral normal ou simétrico em relação ao lado contralateral sadio o teste é positivo (Figuras 1 e 2$)^{(3)}$. 


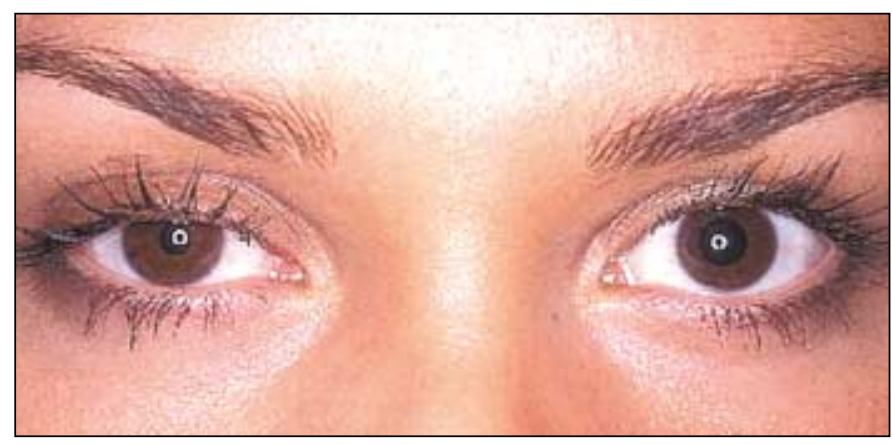

Figura 1 - Ptose mínima à direita

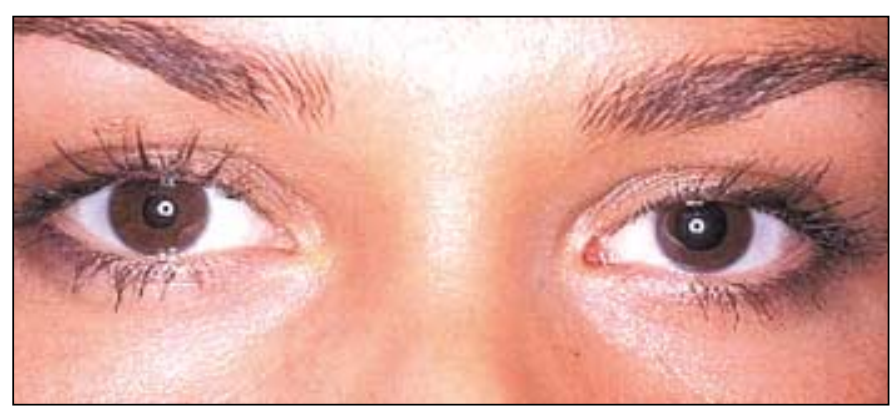

Figura 2 - Elevação palpebral após instilação de fenilefrina $10 \%$

\section{OBJETIVOS}

Relatar a utilização da ressecção do MM-C no tratamento da blefaroptose, descrever algumas alterações técnicas do procedimento cirúrgico e discutir suas vantagens, como por exemplo, baixa incidência de complicações.

\section{MÉTODOS}

Trinta e oito pacientes foram submetidos a ressecção do MM-C para correção cirúrgica de ptose palpebral no período entre 1996 e 2001.

A posição da pálpebra superior foi avaliada utilizando-se a distância margem-reflexo, ou seja, a medida da distância entre o reflexo luminoso corneal e a margem palpebral superior em posição primária do olhar (PPO). A cirurgia foi realizada segundo a técnica descrita por Putterman com algumas modificações técnicas.

A intervenção pode ser realizada sob anestesia local ou geral, sendo esta última indicada para crianças. Injeção de lidocaína a 2\% com adrenalina a 1: 200000 é feita no subcutâneo da pálpebra superior (PS), logo acima da margem palpebral. Após sua eversão com a ajuda de um fio de tração, seda 4-0, passado acima da margem palpebral e um retrator de Desmarres, nova infiltração é realizada na conjuntiva logo acima do tarso (Figura 3). Incisão da conjuntiva em toda extensão horizontal da base superior do tarso é realizada com bisturi lâmina 15 e dissecção superiormente em bloco do MM e da

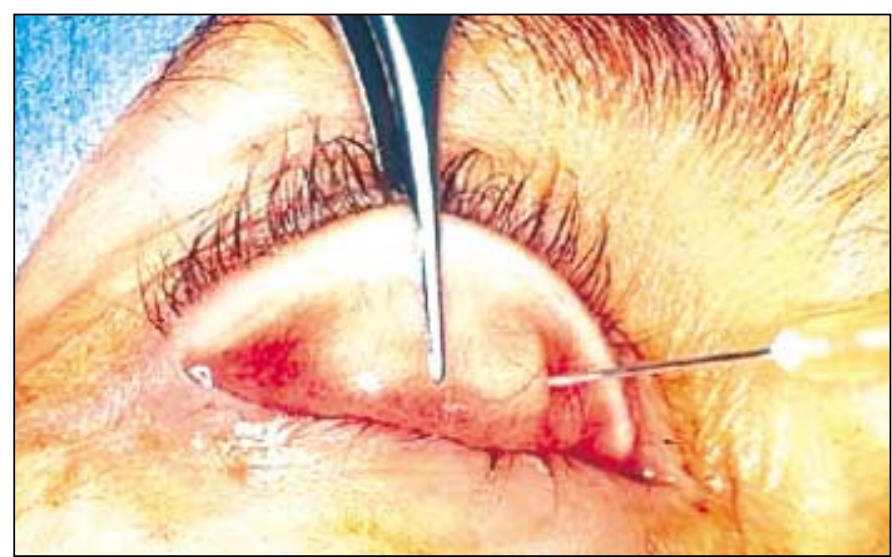

Figura 3 - Infiltração conjuntival

conjuntiva. Duas pinças hemostáticas são utilizadas para prender as extremidades medial e lateral deste bloco e assim facilitar esta dissecção (Figura 4).

O MM é facilmente separado da aponeurose do MLPS. A ressecção de um segmento de MM-C é realizada (Figura 5); a medida da porção ressecada baseia-se no resultado do teste da fenilefrina durante a avaliação pré-operatória.

O valor da elevação produzido pelo teste da fenilefrina determinou a quantidade de tecido a ser ressecado. Por exemplo, se a pálpebra ptótica elevou-se ao mesmo nível do lado normal, a quantidade ressecada foi de $8,0 \mathrm{~mm}$. Nos casos que a pálpebra elevou-se acima do nível contralateral, a ressecção foi entre 6,0 a 7,0 $\mathrm{mm}$. E no caso de hipocorreção durante o teste com fenilefrina, a ressecção foi maior, entre 9,0 e 10,0 mm. Cinco pacientes que apresentaram teste positivo, porém com fraca elevação da PS foram submetidos a ressecção de $10,0 \mathrm{~mm}$.

A sutura era contínua, unindo as margens da conjuntiva,

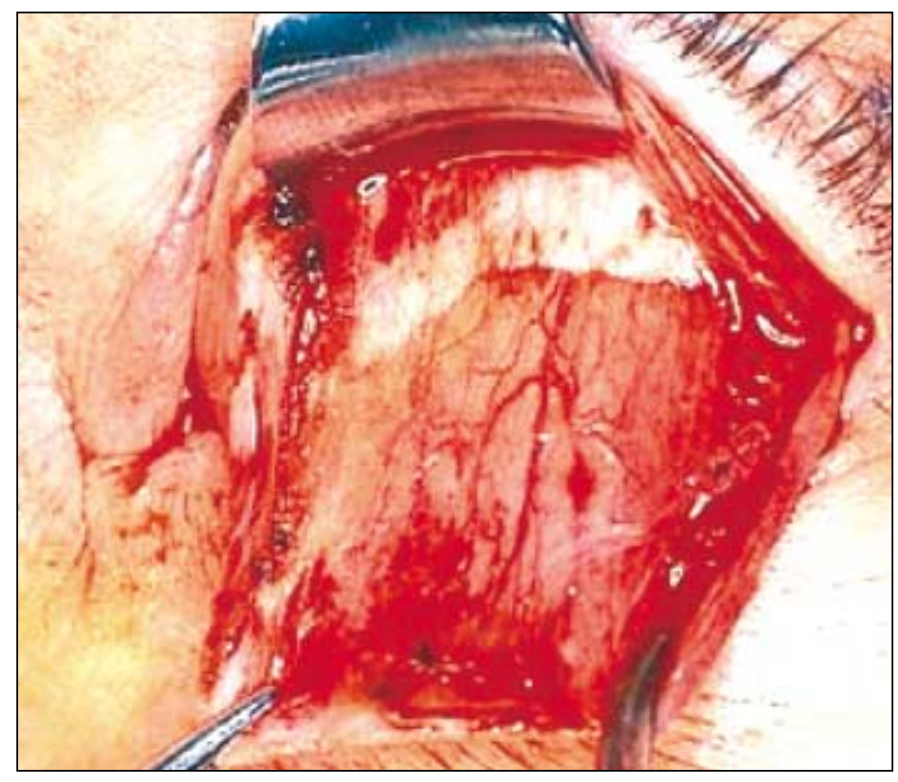

Figura 4 - Separação em bloco: músculo de Müller-conjuntiva 


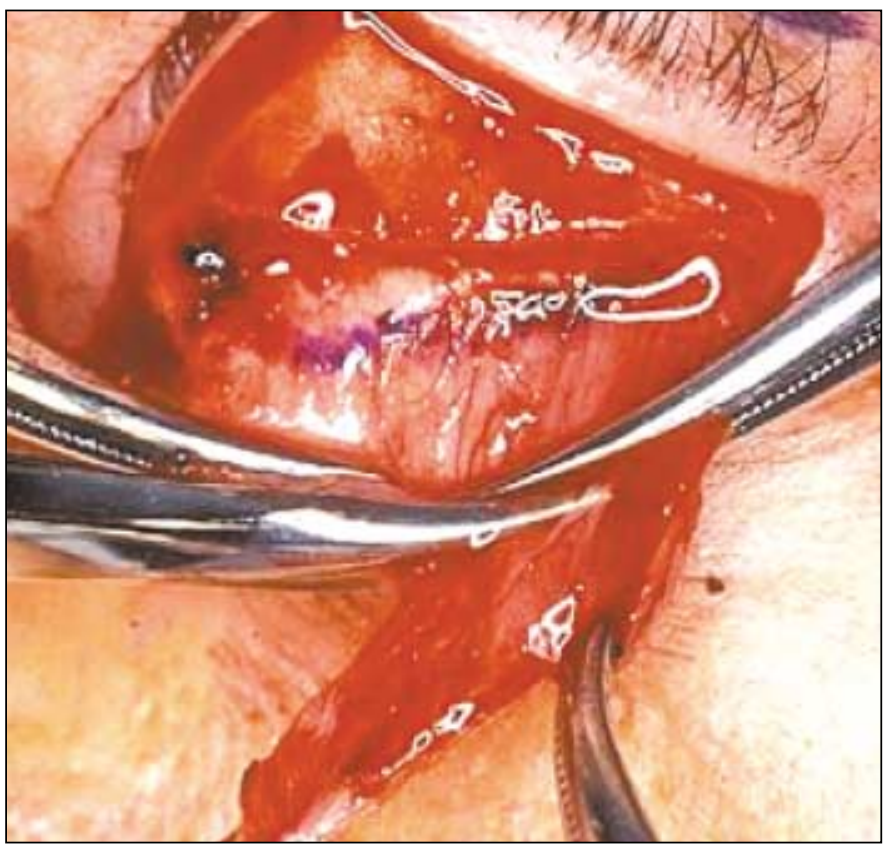

Figura 5 - Ressecção em bloco: músculo de Müller e conjuntiva

MM e base do tarso (Figura 6) em toda extensão da ferida cirúrgica. As duas extremidades da sutura transfixavam toda a espessura palpebral e eram fixadas na pele para evitar o contato com a superfície ocular. Pode ser utilizado um fio absorvível (vicryl 6-0) ou fio inabsorvível (prolene 5-0 ou 6-0).

Os critérios de bom resultado que utilizamos foram a posição da margem palpebral superior a 2,0 $\mathrm{mm}$ abaixo do limbo corneal ou a simetria com o lado contralateral.

Em casos de hipocorreção no pós-operatório imediato, as extremidades da sutura foram tracionadas, elevando-se a margem palpebral superior, melhorando o resultado cirúrgico. Nos casos de hipercorreção, deve-se realizar uma tração na pálpebra superior para baixo, podendo ser feita com a ajuda de um fio de tração, seda 4-0, na borda palpebral nas primeiras $48 h^{(3-4)}$.

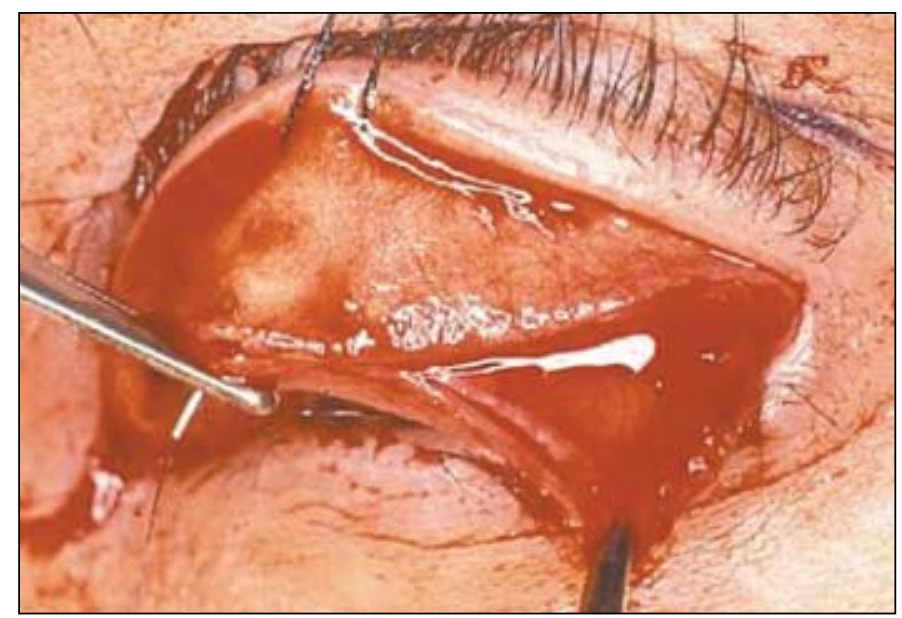

Figura 6 - Sutura contínua unindo tarso, músculo de Müller e conjuntiva
Inicialmente o grupo era composto por 63 pacientes. Dois pacientes não foram incluídos neste trabalho pois durante o ato cirúrgico observou-se deiscência da aponeurose do MLPS e optou-se pela fixação da aponeurose à base do tarso associado à ressecção do MM-C. Vinte três pacientes também foram eliminados devido ao seguimento pós-operatório inferior a 3 semanas, apesar de apresentarem boa simetria com o lado contralateral normal.

Os trinta e oito pacientes, 39 pálpebras, do estudo apresentavam teste da fenilefrina $10 \%$ positivo na avaliação préoperatória, porém 5 destes apresentaram fraca elevação.

Vinte sete pacientes eram do sexo feminino e 11 do sexo masculino. A idade variou entre 11 e 73 anos (média: 42 anos). Todos pacientes (39 pálpebras) apresentavam blefaroptose variando entre 1,0 e 3,0 $\mathrm{mm}$ (média: 2,0 $\mathrm{mm}$ ), 37 unilateral e um caso bilateral. Trinta e cinco pacientes apresentavam função do MLPS igual ou superior a $10 \mathrm{~mm}$ e 2 pacientes tinham esta medida inferior a $10 \mathrm{~mm}$ (Tabela 1).

Doze casos eram congênitos e 26 adquiridos. As formas adquiridas eram assim relacionadas: 10 casos de síndrome de Claude Bernard-Horner pós cirurgia cervical ou região apical do tórax, 2 pacientes com história prévia de cirurgia ocular, descolamento de retina e cirurgia filtrante, 4 pacientes usuários de lente de contato rígida. Um paciente apresentava seqüelas da doença de Graves: exoftalmia sem indicação cirúrgica, retração palpebral superior e inferior à direita e blefaroptose à esquerda. Três pacientes apresentavam dermatocálaze associada à blefaroptose (Tabela 2).

Anestesia geral foi realizada em apenas 3 casos, por se tratarem de crianças.

A ressecção do MM-C variou de 6.0 a $10.0 \mathrm{~mm}$, dependendo do resultado ao teste da fenilefrina na avaliação pré-operatória.

Uma paciente foi submetida à blefaroplastia das quatro pálpebras por via cutânea e outra foi submetida à blefaroplastia das pálpebras superiores no mesmo ato cirúrgico.

Foi utilizado fio inabsorvível: prolene 6-0 em 15 pálpebras, prolene 5-0 em 11 pálpebras; fio absorvível (vicryl 6-0) em 10 pálpebras. A sutura cutânea na blefaroplastia foi realizada com seda 6-0.

O seguimento pós-operatório variou entre 1 mês e 24 meses (média: 12,5 meses).

\begin{tabular}{|c|c|c|}
\hline \multicolumn{3}{|c|}{ Tabela 1. Características gerais } \\
\hline $\begin{array}{c}\text { Idade } \\
\text { (Média: } 42 \text { anos) }\end{array}$ & $\begin{array}{l}\text { Mínima } \\
11 \text { anos }\end{array}$ & $\begin{array}{l}\text { Máxima } \\
73 \text { anos }\end{array}$ \\
\hline $\begin{array}{c}\text { Sexo } \\
\text { (38 pacientes) }\end{array}$ & $\begin{array}{l}\text { Masculino } \\
11(29 \%)\end{array}$ & $\begin{array}{l}\text { Feminino } \\
27(71 \%)\end{array}$ \\
\hline $\begin{array}{l}\text { Pálpebra afetada } \\
\text { (38 pacientes) }\end{array}$ & $\begin{array}{l}\text { Unilateral } \\
37 \quad(97,3 \%)\end{array}$ & $\begin{array}{l}\text { Bilateral } \\
1 \quad(2,7 \%)\end{array}$ \\
\hline $\begin{array}{l}\text { Grau de ptose } \\
\text { (Média: } 2,0 \mathrm{~mm} \text { ) }\end{array}$ & $\begin{array}{l}\text { Mínimo } \\
1,0 \mathrm{~mm}\end{array}$ & $\begin{array}{l}\text { Máximo } \\
3,0 \mathrm{~mm}\end{array}$ \\
\hline $\begin{array}{c}\text { Função do MLPS } \\
\text { (38 pacientes) }\end{array}$ & $\begin{array}{c}\text { Inferior a } 10 \mathrm{~mm} \\
2(5,3 \%)\end{array}$ & $\begin{array}{c}\text { Igual ou maior a } 10 \mathrm{~mm} \\
36(94,7 \%)\end{array}$ \\
\hline
\end{tabular}


Tabela 2. Tipos de blefaroptose

\begin{tabular}{llr} 
Tipos de ptose & $\begin{array}{r}\text { Número de } \\
\text { pacientes }\end{array}$ \\
Congênita & $12(31,5 \%)$ \\
Adquirida & Sem doença ocular associada & $6(16,0 \%)$ \\
& $\begin{array}{l}\text { Síndrome Claude Bernard-Horner } \\
\text { pós-cirurgia }\end{array}$ & $10(26,3 \%)$ \\
& Cirurgia ocular prévia & $2(5,3 \%)$ \\
& Usuário de lente de contato & $4(10,5 \%)$ \\
& Seqüela de Doença de Graves & $1(2,6 \%)$ \\
& Dermatocálaze associada à ptose & $3(8,0 \%)$ \\
\hline
\end{tabular}

\section{RESULTADOS}

A ressecção do $\mathrm{MM-C}$ apresentou bom resultado em 33 pálpebras das 39 operadas $(85 \%)$. A pálpebra superior foi elevada ao nível desejado simetricamente com o lado contralateral.

Seis pacientes apresentaram hipocorreção no pós-operatório; em um destes casos, foi observado alteração anatômica da aponeurose do MLPS durante o ato cirúrgico.

\section{DISCUSSÃO}

A ressecção do MM e da conjuntiva tem sido utilizada em casos bem selecionados de blefaroptoses congênitas ou adquiridas com altas taxas de sucesso. A avaliação pré-operatória é fundamental para uma indicação precisa e um resultado satisfatório no pós-operatório.

Todos pacientes deste estudo apresentavam blefaroptose variando de 1,0 e 3,0 mm (média: 2,0 mm) e teste da fenilefrina positivo, sendo que 5 pacientes apresentaram fraca elevação da pálpebra superior quando comparada com o lado normal. É importante salientar que a quantidade de elevação produzida pelo teste da fenilefrina determinou a quantidade de tecido a ser ressecado. Pálpebras menos responsivas ao teste foram submetidas à maior ressecção tecidual.

Vários autores descreveram modificações na técnica originalmente descrita por Putterman e Urist com o objetivo de facilitar o isolamento do MM e da conjuntiva, diminuir a possibilidade de hipocorreção, diminuir o trauma cirúrgico e simplificar o procedimento.

As modificações realizadas na técnica original no presente trabalho também tiveram o objetivo de facilitar sua execução ${ }^{(3-4)}$. Não acreditamos ser necessário a utilização da sutura com fio de seda no início da cirurgia para delimitar o tecido a ser ressecado e/ou para facilitar a separação do MM da aponeurose do MLPS. Utilizamos duas pinças hemostáticas para preender as extremidades medial e lateral do bloco MM-C e não uma pinça especial como a descrita por Putterman e Urist ${ }^{(2)}$.

Weinstein e Burger descreveram pela primeira vez a utilização de sutura de tração, tornando mais fácil a separação do complexo MM-C ${ }^{(5)}$.

Dresner utilizou suturas de tração e desenvolveu uma fórmula com diferentes quantidades de ressecção dependendo do grau de blefaroptose, com o objetivo de obter uma simetria perfeita entre as duas pálpebras, obtendo uma diferença de simetria de 0,5 mm em $84 \%$ das pálpebras operadas e de $1,0 \mathrm{~mm}$ em $11 \%{ }^{(6)}$.

No presente estudo, das 39 pálpebras operadas, $33(85 \%)$ apresentaram simetria com o lado contralateral; Putterman e Fett, em 10 anos de estudo, obtiveram uma taxa de $90 \%$ de sucesso cirúrgico(7).

Outras vantagens desta técnica a serem destacadas são: fácil execução e rapidez. É possível a associação com outras cirurgias, como, por exemplo, a correção de blefaroptose e blefaroplastia.

Alguns autores realizaram um estudo comparando dois grupos: o primeiro foi submetido à blefaroplastia e ressecção do MM-C durante o mesmo ato cirúrgico e o segundo somente a ressecção do MM-C. Esses autores constataram menor elevação palpebral no primeiro grupo independente da quantidade de tecido ressecado. Uma das explicações possíveis para este resultado é a presença de edema importante após blefaroplastia, dificultando o avanço da aponeurose em direção à placa tarsal. Durante a blefaroplastia o sulco palpebral era refeito, unindo a aponeurose do MLPS ao músculo orbicular; a cicatrização desta sutura pode também ser responsável pela menor elevação da PS no grupo de pacientes que foram submetidos à blefaroplastia ${ }^{(8)}$.

Glatt et al acreditam que a técnica da ressecção do MM-C poderia ser utilizada para correção da blefaroptose involucional, que é causada por uma deiscência ou enfraquecimento da aponeurose do MLPS, sendo realizado um encurtamento da lamela posterior e indiretamente ocorreria um avanço da aponeurose em direção à placa tarsal. Várias são as vantagens desta técnica quando comparada com técnicas que atuam na aponeurose do MLPS: maior rapidez, maior conforto para paciente, menor trauma cirúrgico e maior previsibilidade pósoperatoria $^{(9)}$. É possível avaliar o resultado cirúrgico logo nos primeiros dias, pois o edema é bem reduzido.

Seis pacientes deste estudo evoluíram com hipocorreção no pós-operatório, sendo que destes, um apresentava alteração anatômica da aponeurose do MLPS que foi constatado durante o procedimento cirúrgico. A aponeurose do MLPS apresentava-se fina e infiltrada por gordura. Alguns autores relacionam a fraca resposta ao teste da fenilefrina a uma fraca função do músculo de Müller, podendo ser causada por uma infiltração gordurosa ${ }^{(6)}$.

\section{CONCLUSÕES}

A ressecção do MM-C é um procedimento útil quando realizada em pacientes bem selecionados, ou seja blefaroptose variando de 1,0 e 3,0mm e boa função do MLPS. A vantagem desta técnica, se comparada à descrita por Fasanella e Servat em 1961, é a preservação da placa tarsal. Outra vantagem é a possibilidade de fornecer um resultado bastante previsível quando comparada com os procedimentos que utilizam a aponeurose do MLPS. 


\section{ABSTRACT}

Objective: To evaluate the results of Müller's muscle-conjunctival resection for correction of blepharoptosis and to discuss the advantages of this procedure. Methods: 38 patients (39 eyelids) were submitted to Müller's muscle-conjunctival resection. Blepharoptosis varied from $1.0 \mathrm{~mm}$ to $3.0 \mathrm{~mm}$ (mean: $2.0 \mathrm{~mm}$ ). The amount of eyelid elevation produced by phenylephrine guided the amount of tissue to be resected. Result: 33 eyelids $(85 \%)$ treated with this procedure were cosmetically acceptable. Conclusions: Müller's muscle-conjunctival resection procedure is a relatively simple technique for blepharoptosis, with good levator function and positive $10 \%$ phenylephrine test. The advantages are: preservation of tarsus and predictable results.

Keywords: Blepharoptosis/surgery; Eyelids/surgery; Conjuctiva/surgery; Phenylephrine/diagnostic use; Treatment outcome

\section{REFERÊNCIAS}

1. Fasanella RM, Servat J. Levator resection for minimal ptosis: another simplified operation. Arch Ophthalmol. 1961;65:493-6.

2. Putterman AM, Urist MJ. Muller muscle-conjunctiva resection. Technique for treatment of blepharoptosis. Arch Ophthalmol.1975;93(8):619-23.

3. Morax S, Doukhan A. [Conjunctiva Muller's muscle monobloc resection in the surgical treatment of minor ptosis]. J Fr Ophtalmol. 1986;9(6-7):455-60. Francese.

4. Morax S. Ptosis et complications. In: Adenis JP, Morax S. Pathologie orbitopalpébrale. Paris: Masson; 1998. p.227-60.

5. Weinstein GS, Buerger GF. Modifications of the Muller's muscle-conjunctival resection operation for blepharoptosis. Am J Ophthalmol. 1982;93(5):647-51.

6. Dresner SC. Further modifications of the Muller's muscle-conjunctival resection procedure for blepharoptosis. Ophthalmic Plast Reconstr Surg. 1991;7(2):114-22.

7. Putterman AM, Fett DR. Muller's muscle in the treatment of upper eyelid ptosis: a ten-year study. Ophthalmic Surg. 1986;17(6):354-60.

8. Brown MS, Putterman AM. The effect of upper blepharoplasty on eyelid position when performed concomitantly with Muller muscle-conjunctival resection. Ophthalmic Plast Reconstr Surg. 2000;16(2):94-100.

9. Glatt HJ, Putterman AM, Fett DR. Muller' muscle-conjunctival resection procedure in the treatment of ptosis in Horner's Syndrome. Ophthalmic Surg. 1990;21(2):93-6. 